\title{
The Internet and the Madisonian Cycle: Possibilities and Prospects for Consultative Representation
}

\author{
David Lazer, Michael Neblo, and Kevin Esterling ${ }^{1}$
}

The Internet has the potential to transform our democracy-a potential that has received substantial scholarly attention (e.g., DiMaggio, Hargittai, Neuman, and Robinson 2001; Hindman 2009; Bimber 2003; MayerSchönberger and Lazer 2007). This attention has focused on the potential transformational effects of the technology on civil society and, in the political realm, on the ways that the Internet might transform political discourse. Researchers have devoted less attention, however, to how the Internet might transform existing institutions for connecting citizens to elected officials. This relationship is the fundamental building block of a representative democracy, and it has come under increasing strain as our country has grown from a few million to a few hundred million, as congressional districts have swelled from a few tens of thousands to well over 600,000 , as the number of matters that the state is involved in has multiplied, and as policy problems have grown more complex. Contemporary Washington politics is now almost exclusively the domain of entrepreneurial legislators, highly trained committee staff, legal counsel, agency heads, lobbyists, and expert policy analysts. Today, it is difficult for interested citizens to understand the policy process or have their voices heard in it (Heclo 1974; Lupia and McCubbins 1998). Because of this and other trends, citizens have become increasingly disengaged from the work of Congress.

The Internet offers tools that might help to arrest this trend, to rewire the informational flows undergirding our democracy (Mayer-Schönberger and Lazer 2007), and thus to increase the participation of citizens in the consultative process with their representatives. A well-designed Internet strategy by members of Congress can provide citizens with information that is useful for understanding a policy as it develops and with a way to interact more symmetrically with both their member of 
Congress and with each other. Wisely used, the Internet can reconnect citizens and Congress.

This potential for change has been largely unrealized and unstudied. Although there has been a considerable amount of scholarship on the effects of the Internet on government, governance, and society (e.g., Mayer-Schönberger and Lazer 2007; Bellamy and Taylor 1998; DiMaggio, Hargittai, Neuman, and Robinson 2001; Fountain 2001; Yates, Orlikowski, and Okamura 1999), we have identified little systematic research on how members of Congress use or should use the Internet to provide information to their constituents. This lack of scholarship is matched by a lack of progress by members in using their Web sites.

This lag is unsurprising and significant. Members of Congress are accustomed to and tend to be very good at interacting face to face with constituents. Digital interaction, however, is inherently new terrain for many members, and any new activity entails uncertainty and risk. Implementing innovations and making effective use of them require new knowledge and new operating procedures. As a consequence, adoption of Web technologies is neither automatic nor effortless. As Dawes and her colleagues $(1999,21)$ write, “Throughout our history, developments in technology have emerged much faster than the evolution of organizational forms."

This lag is significant because the widespread adoption and use of Web-based technologies among citizens creates the potential for greater citizen participation in and knowledge and trust of their government. Web technologies allow citizens a kind of access to the government irrespective of their geographic proximity to the seat of government and increasingly irrespective of their wealth and educational level. When citizens have better knowledge of the hard choices Congress often has to make and the rationale that legislators have for making them, many citizens may reinvest their trust in government (Bianco 1994). Wisely used, the Internet can reconnect citizens and Congress in meaningful ways. The lack of the use of the Internet by members is thus potentially a serious missed opportunity for our democracy.

In this chapter, we summarize the results of extensive research we have conducted on the use of the Internet by members of Congress. We begin by discussing a republican deliberative ideal, which we label the Madisonian cycle-a deliberative process that encompasses the representative and the represented. We then turn to a discussion of what members of Congress are actually doing with the Internet, finding that often they are not taking advantage of many of the features of the Internet with their 
official Web sites. This leads to a question: how do members conceive of the potential of the Internet? Our answer is that their conception is predictably narrower and more instrumental than the normative ideal. Because the official Web sites do not allow members to convey different messages to different constituencies, it is often politically counterproductive to put much policy information on the Web site. We then turn to a set of experimental studies we conducted on the potential use of the Internet by members. In these experiments, we conducted randomized experiments with twelve U.S. representatives and one U.S. senator who interacted with constituents in online town hall meetings. Our findings were encouraging: these sessions reached a diverse set of constituents and substantially affect the participation rates, policy knowledge, and support for the member.

\section{The Madisonian Cycle}

The second charge against the House of Representatives is, that it will be too small to possess a due knowledge of the interests of its constituents. It is a sound and important principle that the representative ought to be acquainted with the interests and circumstances of his constituents.

-James Madison, No. 56, The Federalist Papers

I would want to know with the specific issues how they voted, for or against, and why they voted for or against. That's what I want to know, because sometimes when you just hear how the vote went and you see that your representative voted one way or the other, you may get angry or whatever, but if you see why they voted that way, you may be pleased that they would rationalize it out.

-Richmond participant in focus group on Congressional Web sites (Congressional Management Foundation 2001, 4)

Members of Congress have a general duty (and a strong incentive) to enact policies that will be popular in their districts. However, they typically have better information with which to make policy judgments than most citizens do, so they do not simply vote for whatever an uninformed public thinks that it wants at the moment. Members of Congress generally do not and should not assume either the role of a paternalistic "trustee" or a rubber-stamp "delegate" (Pitkin 1967). An alternative model envisions a cycle of deliberation that allows citizens to formulate and communicate their general interests, legislators to debate and craft policies to advance those interests and persuade their constituents of the (sometimes nonobvious) connection between the two, after which the process repeats itself in a cycle of feedback. This picture portrays a more 
Madisonian or "republican" model of deliberative representation (Held 1996).

The Madisonian feedback cycle is implicit in many models of the public-policy process. Citizen engagement is one of the core principles of constitutional democratic government (Bohman and Rehg 1997; Gutmann and Thompson 1997; Habermas 1996, Neblo 2000). However, empirical research on deliberation to date has focused almost exclusively on either deliberation among elites, such as members of Congress (Bessette 1994), or among citizens (Fishkin 1997) rather than between citizens and their representatives. The relative neglect afforded citizenrepresentative deliberation is due to a narrow definition of the term deliberation - that is, one that confines it to cooperative, symmetric communication in real time among a discrete set of people who are trying to solve a common problem. However, the original theorists of deliberative democracy also had something broader in mind-a kind of deliberative culture that includes, in addition to deliberation in the narrow sense, locally asymmetric communication between elements of civil society and government in the service of a larger, ongoing public dialog (Habermas 1996). For example, a policy address or letters to a representative or senator could be understood as contributing to the deliberative cycle in this broader sense.

\section{How Do Members of Congress Conceive of the Internet?}

An examination of official member Web sites indicates that they are not heavily used to enable public discourse. A majority of Web sites do not offer any indication of the member's voting record (Congressional Management Foundation 2001) and do not make their party affiliation obvious on their homepage. In the appendix to this chapter, we offer two case studies of member Web sites. One obstacle is the inertia of senior members (Esterling, Lazer, and Neblo 2011). One communications director we interviewed said that the very senior member she worked for asked to see his Web site (for the first time) because a few constituents complimented it: "He came to me one day. He says, 'I need to see my Web site'-and turns on his TV (laugh)." In this first generation of members, there is a powerful generational effect that will fade as turnover occurs. However, the key question is whether in the long run the strategic interests of members will align with the use of the Internet to enable a discursive process with constituents. We now turn to an examination of those strategic interests. 


\section{Structuring the Discourse: Channeling Social Control over Deliberation}

Any discursive setting requires a medium that provides and constrains opportunities for communication. Key dimensions to any medium for communication relevant to our discussion below is its publicness and its permanence. In the Habermasian ideal-the Parisian cafés—discussion is necessarily semipublic, semiprivate, and ephemeral. Alternative media and forums available in the past include published works (public and potentially permanent), discussions in salons (private and ephemeral), and letters (private and potentially permanent).

Putting aside the normative issues, these two dimensions of communication are important for strategic reasons. The public/private dimension is important because the public aspect of a discussion subjects its participants to social control. Participants in that discussion must necessarily think of the reactions of third parties. In some cases, third parties will be far more important than the immediate parties to a discussion. Will a particular statement be subject to social approval or opprobrium?

The permanent/ephemeral dimension potentially constrains speakers in another fashion-increased intertemporal accountability. This accountability comes from statements that are contradicted by future facts (such as George Bush's "mission accomplished") and that are inconsistent across time (also known as the flip flop).

This analysis highlights that the choice of forum for deliberation is a strategic one. Assuming that actors have a choice of forums that differ in their publicness and permanence, what would they choose? It is not clear that actors necessarily wish to avoid social control because approval may be highly beneficial. For example, Barack Obama's early public and recorded statement in opposition to the war was indisputably beneficial to his political career.

To explore how members of Congress conceived of the potential of the Internet, we conducted interviews with people from ninety-nine separate congressional offices that lasted roughly forty-five minutes each. Although we attempted to recruit a sample reflective of the body, the offices tilted somewhat in the direction of being Democratic and urban; when splitting the sample along these strata, we did not note any significant differences (for details, see Lazer, Mergel, Ziniel, Esterling, and Neblo 2009). These interviews were conducted during the spring and summer of 2006 with congressional staffers who had primary responsibility for the member's official Web site. The interviewee was most commonly the member's press secretary or communications director but also 
included legislative directors and systems administrators. These interviews were transcribed and coded with NVivo.

\section{Conception of the Point of the Web Site}

How do offices conceive of their Web sites? Do they see the Web sites as a means for fostering ongoing discussions with constituents about policy? In fact, few of the people that we interviewed conceived of the Web sites in that fashion. Most offices see the Web sites as a means for (1) delivering services and (2) presenting a sense of who the member is (which does not necessarily involve reference to policy). As one communications director stated, "It's all about making the congresswoman look good." Another communications director, in explaining why the member's Web site did not make clear the party affiliation of the member:

[Y]ou want people to feel comfortable going to it. ... If they're a Democrat and you're a Republican, you don't want it in their face because then they don't want to take the time to learn about you. And ... that's kind of a hospitality question. You don't want people to feel alienated from the moment they open up the Web page.

So from the perspective of many offices, the informational efficiency of party affiliation as a shortcut to understanding a member's positions is a drawback. The worry is that party information will discourage constituents of the other party from viewing the site's content. Thus, for example, an important function of the Web site is to facilitate delivery of constituent services, but some constituents may not feel comfortable approaching an office if they are of the opposite political persuasion. As another interviewee stated, "[W]e want people to know that it doesn't matter what party you are, it doesn't matter what party we are."

In fact, if a Web site spurs a dialog on the political issues of constituents, it is a sign of failure, not success:

$[Y]$ ou can put a lot a information on there, but sometimes you may put something on there that really shouldn't be on there-like ... his stance on abortion. If we put it on there, it's going to cause a bunch of work. It's going to cause a bunch of phone calls and letters that we're going to have to respond to. And ... after the fact, it's like-well, . . . shouldn't of put it up there. So we try to stay away from the controversial issues on the Web site.

In short, most interviewees indicated that conveying policy information on the Web site was exclusively in service of the goal of making the member "look good," as one press secretary states: "I guess the biggest goal is to communicate to the constituents that we're doing a good job. 
Our goal is not to necessarily give the congresswoman's opinion on every issue."

\section{Concern over Opposition Research}

The key mechanism of social control in electoral politics is the ballot. And the vessel of that control is the opposition candidate, who has the incentive to thoroughly examine every statement and political act of a member and to communicate them to voters in as unflattering a light as possible. It is therefore not surprising that many interviewees expressed concern about the potential for the use of content on the Web site for opposition research. One press secretary from an office with a particular paucity of policy-relevant material on its Web site offered a summary of lessons learned from the preceding election:

A concern is that it [the Web site] is so good that it's going to help out opposition research. I don't think ours is that way, but I know our opponent last campaign had a wonderful campaign Web site. And anytime he said anything, he put it on there, and he had a blog, and it was updated daily. And I don't know how much traffic he got, but boy, any time we needed to find something he said, we'd type in what we thought he said in the search engine, and it would pop up. So I don't ever want us to have that happen to our Web site. I mean obviously anything we put on there, we're comfortable defending. . . . But we need to be kind of cognizant that we don't want to just hand over a bunch of opposition research to the other side.

So transparency is potentially damaging for a member because information that is favorable with some constituencies in some circumstances can be recycled by opponents as unfavorable for other audiences. As another interviewee stated, "If you're putting information out to everyone, ... your political opponents get that information too and can try to use that in their own ways." With a controversial issue like abortion, as one interviewee stated, "Unless you're out there taking a lead on it, you're not going to put controversial stuff on your Web site-because it's going to show up in your opponent's ads two years from now." There is also an important temporal dimension. As one individual stated, there is a "fear of being pinned down on an issue" because of earlier statements.

Thus, although the key objective of the Web site is to make a member "look good," there is a significant concern about the possibility that issue-relevant material will be used to make the member look bad by a future opponent. 


\section{Of Media and Message}

The Web site strategy used by various congressional offices is contingent on the circumstances of the particular member in their district. For example, in revealing party affiliation, the partisan leanings of the district are important. The two interviewees below offer opposing cases of congruence between the party affiliations of the member and the district:

We've got a very Democratic district, so it's-I think it makes sense to, you know, have some [party] credentials on there [on the Web site].

Well, in [state X,] being a Democrat doesn't do anything for us politically. In fact, having a D by your name-it's a challenge to get elected. So that's not something that we're ashamed of, by any means, but it's not something we're going to broadcast if we don't need to. . . I I mean, we are a little bit off to the left. So that's not something we put up front.

The second quote above hints at one of the distinctive qualities of the Internet as a means for communication: it does not discriminate among recipients of the message.

The issue of the targeting of communications becomes especially important with controversial issues, where significant numbers of constituents might be alienated by a position but others might approve, as the following interviewees highlight:

The congresswoman may have to take a very tough position on an issue because she feels that is the right position to take on that particular issue. But we may not actively publicize it and promote it outside of certain constituencies.

[Do you have all of your press releases that you have ever done up here?] Not all of them. . . Some controversial things we won't put on there. We'll just send them to people who want to know.

That is, certain types of messages should go only to particular individuals.

The wholesale nature of the official Web site is therefore seen as a significant drawback for certain types of messages. As discussed above, other media allow customization of messages, with email and letters being at the opposite end of the spectrum. As this one informant suggests, policy information is conveyed differently in emails and on the Web site:

[Question: How's the content (that people get from e-mails) different, if at all, from the content that's up on the Web site?] Very different. We'll answer individual emails with strong policy statements.

The Web site is seen by many offices as limited by its wholesale nature. IT does not allow them to target different constituencies or individuals with different messages. 


\section{An Alternative Model of Online Deliberation}

Although official Web sites may not offer representatives a means for deliberating with constituents about issues of the day, the Internet and other technologies offer other ways for them to connect. To explore one means, we conducted a series of online town hall meetings between constituents and members of Congress and were encouraged about the possibilities of an Internet-enabled democracy. Space does not allow a full exposition of our analyses, which were published in several papers, but here we provide a summary of the methodology and our key results, referencing the relevant papers.

\section{Research Design}

Our research objective was to assess the effect of participation in online town hall meetings on participating constituents. To evaluate the potential effect, we recruited twelve U.S. representatives and one U.S. senator to participate in twenty-one online sessions. ${ }^{2}$ The topic for discussion in the session with the representatives was immigration and with the senator detainee policy. The twenty sessions with representatives were conducted in the summer of 2006 and had about twenty participants each; the one session with the senator was conducted in the summer of 2008 and had 193 participants.

A town hall meeting was structured so that the member of Congress could speak via "voice over Internet protocol" and their constituents could hear their comments over their computers (their statements were also transcribed in real time for participants to read in case audio problems were encountered). Participants submitted statements or questions for the member. These were managed by someone on the research team, who posted them in order to the member, removing redundant or offtopic questions.

To evaluate the effects of participation in a session, we needed to construct a counterfactual. After recruiting potential participants and administering a background survey, we randomly assigned individuals to one of two control conditions or to an online town hall meeting with their member. Individuals who participated in the meeting were given two-page background materials before the meeting and later participated in an online town hall meeting with their member. The two control conditions were meant to distinguish between the effects of the background materials and actual town hall meeting. In control condition 1 , participants were given the background materials, and in control 
condition 2, they were given nothing. One week after the session, all subjects were given another survey, and immediately after the election, a final survey.

The mode of inference was based on a comparison of the treatment group to the two control groups. Inference was complicated by the fact that we could not control whether individuals who were invited to a session actually showed up. We discuss the statistical methodology we developed to deal with this endogeneity in Esterling, Neblo, and Lazer (2011a). Below we summarize our key findings.

\section{Key Findings}

\section{The online townhalls drew diverse participants.}

As noted above, not all individuals who were invited to participate actually showed up for the town hall meeting. Who chooses to deliberate (Neblo, Esterling, Kennedy, Lazer, and Sokhey, 2010)? There is a twofold concern. The first is that online participation, generally, will reflect the digital divide, amplifying existing participation rates along various socioeconomic strata. The second is that deliberative opportunities naturally tend to select an unrepresentative array of people, again magnifying existing participation inequalities. The intersection of online with deliberation thus has a double potential for increasing existing political inequalities.

Our findings were generally reassuring that this is not the case. We found that of seven demographic predictors of lower participation rates-youth, belonging to a racial minority, being female, lower rates of attendance at religious services, weak partisan identification, low income levels, and low education levels-only education has the predicted association with choosing to participate in one of these sessions. The other six factors actually had the opposite sign than that predicted (although not significantly in all cases). Further, we found that individuals who expressed frustration with the political status quo- "stealth democrats" (see Hibbing and Theiss-Morse 2002)—were far more likely to choose to participate.

This finding does not eliminate the concern that online town hall meetings will amplify existing political inequalities because that inequality may be driven by dimensions of the process. For example, if online town hall meetings were to become standard practice for members of Congress, how would they recruit participants? Many of these mechanisms of recruitment would naturally create certain inequalities in par- 
ticipation. However, our findings suggest that is not inherent in the medium and that it offers the potential of reaching individuals who are currently not deeply engaged in our democracy.

\section{Participation in the online town hall meetings increased other forms of political participation.}

What effect did the sessions have on political participation after the town hall meetings? Several measures could be examined, and all suggest that participation levels increased. Voting rates increased-from 77 percent for controls to 82 percent for treatment subjects. And although 41 percent of the control subjects reported not closely following the election, this was the case for only 23 percent of the treatment subjects (see Lazer, Neblo, Esterling, and Goldschmidt 2009). We also found dramatic increases in the probability of talking about the policy in question. For the sessions with the senator, we included a series of questions about the individuals with whom the survey participant talks to about politics, and we found that the probability of talking about the senator and about detainee policy nearly doubled (see Lazer, Sokhey, Neblo, and Esterling 2010). An important secondary implication of this finding is that the sessions affected quite a few people indirectly-perhaps significantly more than participated directly.

\section{Participation in the town hall meetings increased policy knowledge.}

One of the key outcomes of participation in a deliberative session is whether it increases policy knowledge. To that end, we asked six questions about immigration policy (example: "Under current law, is it a felony to reside illegally in the United States?”). We found that participants had a 10 to 20 percent increased probability of giving a right answer relative to (full) controls (Esterling, Neblo, and Lazer 2011b). We did not find that this effect was mediated by whether the member mentioned the particular fact in the session. Improvement seemed to be driven by the motivation provided by the prospect of participating, combined with providing background materials that provided the relevant information.

Participants were more likely to vote for their member and to take his or her position on the issues discussed.

A key issue is whether the use of a particular modality of communication with constituents is consistent with the strategic communication needs of a member. Our results suggest this is the case. The probability that a 
control subject would vote for the member was 49 percent and that town hall meeting participants would vote for the member was 56 percent. The effect on swing voters was particularly dramatic. An individual predicted to have a 50 percent chance of voting for the member in the control condition (based on presession survey questions, such as party affiliation), had a 73 percent chance of voting for the member after having participated in the town hall meeting. Similarly, there were increased positive sentiments about the member across the board-big increases in approval rating (from 46 percent to 62 percent) and in trust that the member would "do what is right" all or most of the time (from 38 percent to 52 percent). There were also big increases in the fraction of participants describing the member as trustworthy, accessible, compassionate, fair, hardworking, understands people like me, knowledgeable, and qualified (with percentage increases ranging from 16 percent to 32 percent). We observed similar increases in the large session with the senator, suggesting that these effects scale with larger session size, which should make them a practical communication tool for members.

In short, these findings suggest that online town hall meetings are powerfully consistent with the strategic imperative of the particular members to communicate with constituents. They were also very popular with the constituents who participated, where 95 percent of participants in the session with the representative and a remarkable 99 percent of participants in the session with the U.S. senator indicated interested in participating in similar sessions in the future. The qualitative comments that people offered were similarly positive. As one participant wrote, "I believe we are experiencing the one way our elected representatives can hear our voice and do what we want.”

\section{Conclusion}

Deliberative theory in a republic needs to encompass the relationship between the representative and the represented. The Internet, as a technology, offers the potential for deliberation and consultation to scale up to the magnitude and complexity of the modern world. The above analysis offers a mixture of pessimism and optimism in the reality and potential of the Internet in enabling the Madisonian cycle. The current reality of how members of Congress use their Web sites is not encouraging. There is relatively little policy content on Web sites, even to the point 
that many members do not even make their party affiliation clear on their Web sites. Our data suggest that this is an unsurprising consequence of the strategic use of the Internet as a communication medium by members. The official Web sites do not allow members to customize their message to particular individuals-a conservative Republican sees the same Web site as a liberal Democrat. As a result, there is a significant danger that the Web site will alienate constituents if it offers clear information on where the member stands on an issue. The permanence of the medium also means that the likelihood that statements could be used for opposition research at some undetermined point in the future is high. Thus, although recent election cycles have highlighted the importance of the Internet in the electoral process, it is less clear what the potential is with respect to enabling a consultative process between representatives and citizens in the United States.

Our optimism comes from the model of deliberation that online town hall meetings represent. Our experiments suggest that these online meetings can reach a diverse set of people and can be especially effective at recruiting individuals who are alienated from politics. These sessions increased policy knowledge, mobilized participation more generally, and could fit with the strategic communication objectives of members. The model we offer is not meant to be limited to the technical details of the sessions that we hosted. Rather, the sessions demonstrate that current communication technology allows members of Congress to reach into the living rooms of their constituents to facilitate a genuinely deliberative dialog. There is room for improvement from a normative point of view. For practical reasons, these town hall meetings did not allow easy followup questions to the member by the questioner, so a discursive back and forth between a member and a particular constituent was not possible. Closely related to this was the fact that the bandwidth from constituent to member was limited to text, engineering an unnecessary asymmetry between the member and his or her constituents. These were design choices that were based on constraints that existed when we conducted these experiments, but they are not inherent to the medium. More research needs to be done to make these kinds of sessions effective.

It is also not clear what design choices are in the interest of members to make. For example, one of the essential features of the online sessions was the control of the sessions by a neutral party. The audience was not preselected to be sympathetic to the member, and the questions were not picked to make the member look good. However, the Internet does enable an invisible, potentially insidious control of the deliberative 
process. We suspect that this would be counterproductive. The authenticity of these sessions enhanced their effect on constituents in a way that was productive for the member (even if it occasionally left them confronting uncomfortable questions in the actual session). Much like official Web sites, members have a set of choices about whether and how to use the Internet for authentic deliberation. Our findings suggest that there is a pathway that will both enhance our democracy and be consistent with the reelection objectives of members.

Further, and critically from the perspective of the preceding analysis, participants almost universally approved of the sessions and generally emerged with higher approval of their member of Congress. The members who participated also reported that the town hall meeting was a valuable way to hear about the concerns of their constituents. In short, this may be a type of online forum in which both representatives and citizens are motivated to participate in. This is not to say that online town hall meetings offer the complete answer to creating a consultative process to the legislature, but our results indicate that they offer a fruitful path forward.

\section{Appendix}

\section{A Case Study of an Official Member Website}

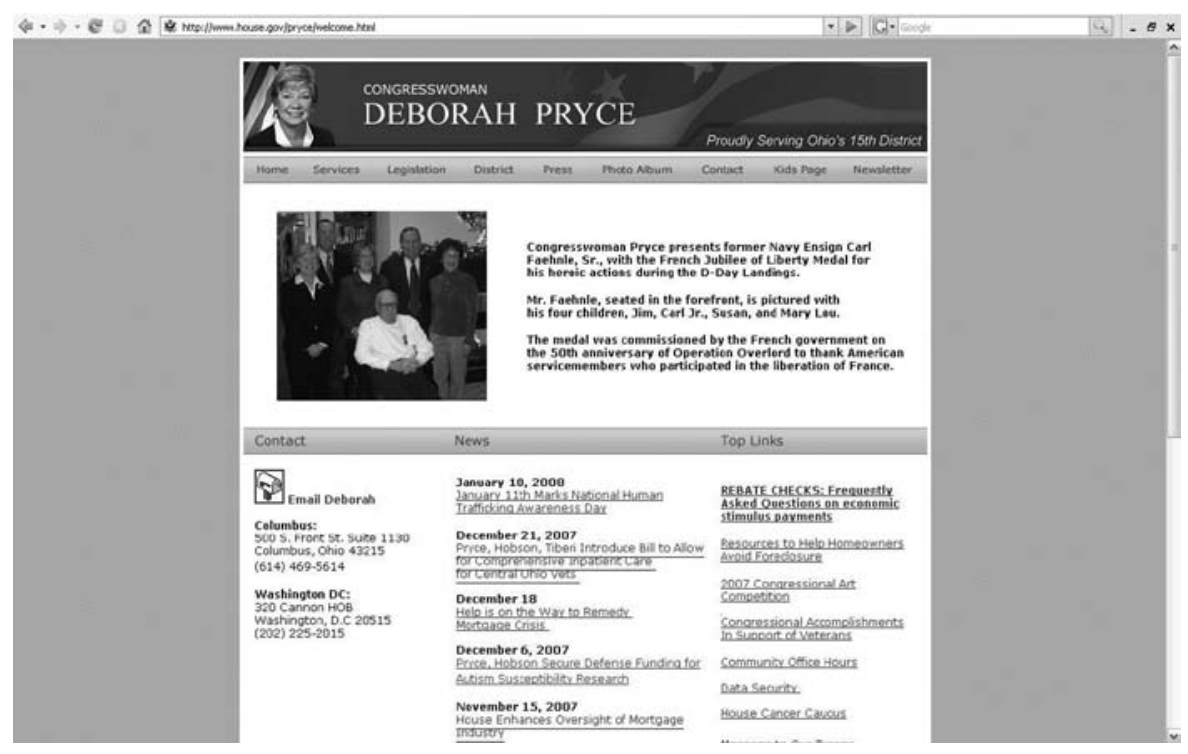


This is the home page of Congresswoman Deborah Pryce. The home page contains the most current press releases but lacks a search tool for users to find specific issue content within the press releases. Congresswoman Pryce's political party is not immediately clear. There is no link to an issues page, but clicking the legislation link brings the reader to the page below.

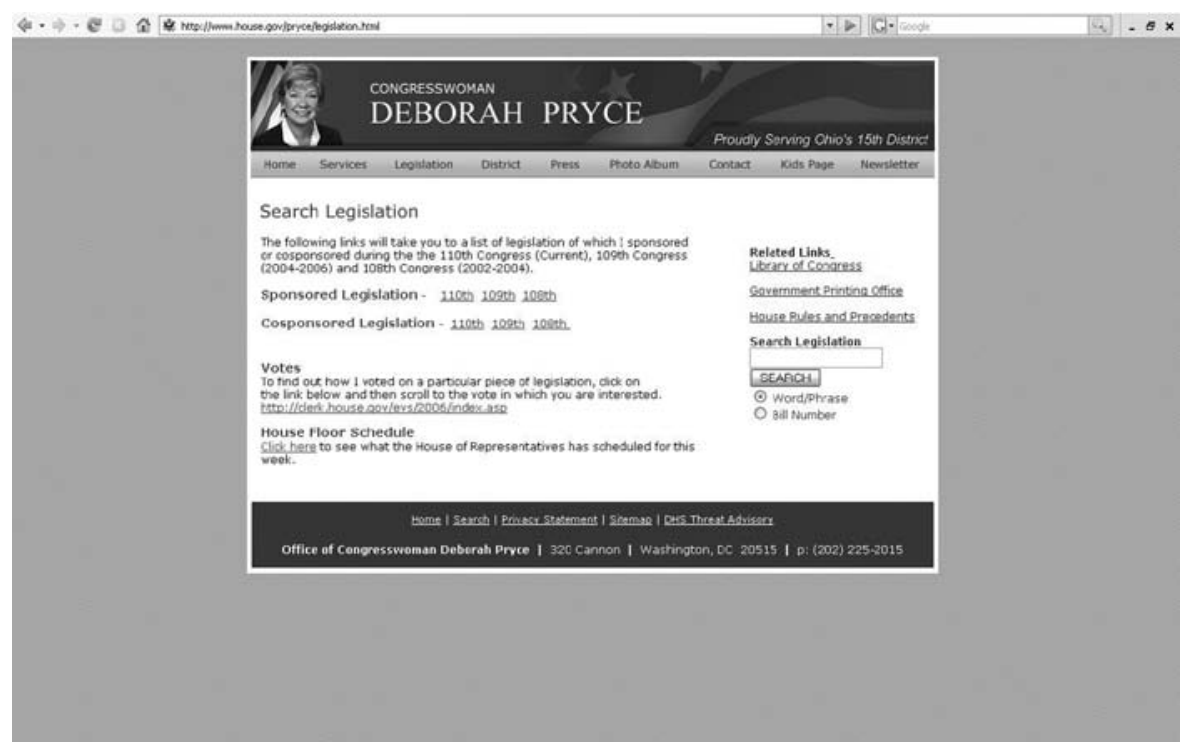

The Legislation page contains links to Congresswoman Pryce's sponsored and cosponsored bills and voting record through the Thomas system and the Clerk of the House Web sites. Although the link to Thomas provides collections of the congresswoman's sponsored bills and the link to the clerk can collect her voting records, no additional information is provided by the congresswoman's own Web site about her legislative priorities, rationales for the legislation she sponsors, or explanations of her vote choice. 


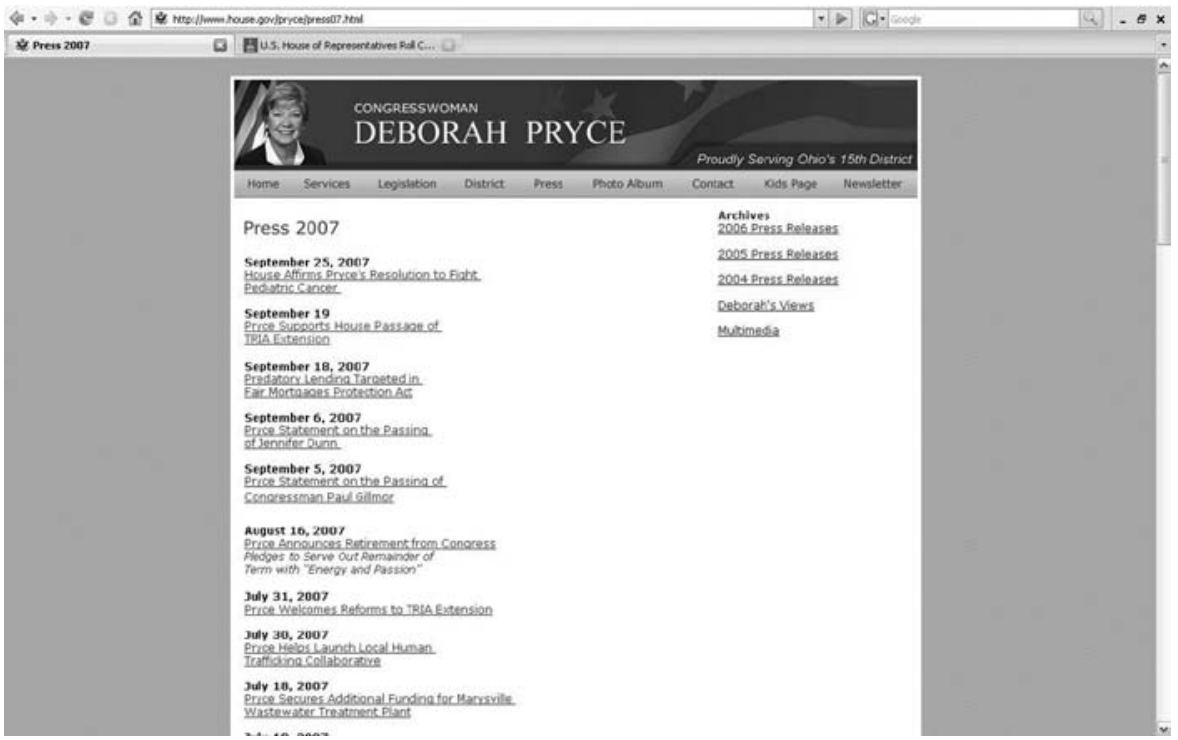

Clicking on the Press link brings the reader to a page of press releases. Press releases are provided for the past four years, but there is no tool for searching through the press releases by issue content. On the right side of the page, there is a link to a page called Deborah's Views. Clicking on the link brings the reader to the page below.

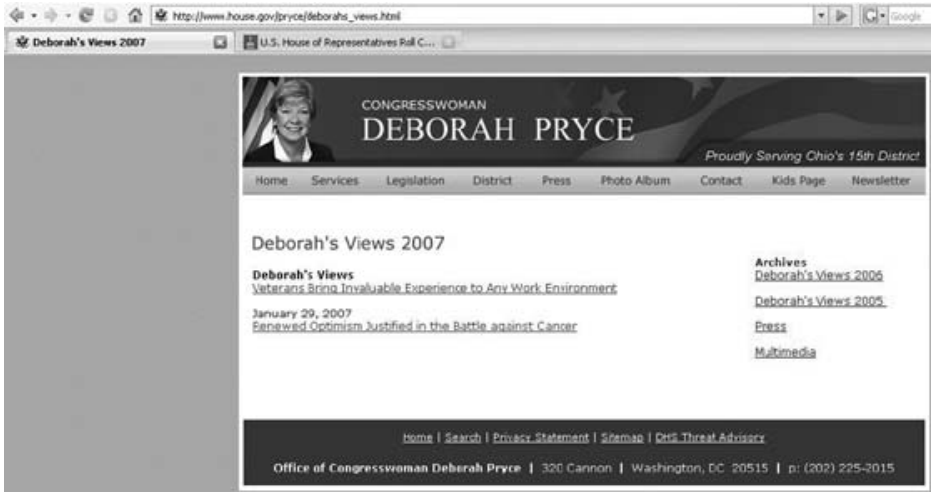


This is the Deborah's Views page provided in early 2008. The only two views listed ("Veterans Bring Invaluable Experience to Any Work Environment" and "Renewed Optimism Justified in the Battle against Cancer") are politically uncontroversial. The lack of views and press releases after September 2007 may be explained by the congresswoman's decision not to seek reelection, but there is no evidence that she ever had a page explaining her issue positions or justifying her vote choices. This lack of policy information may reflect the competitive nature of her Columbus district. Congresswoman Pryce's district was extremely competitive in 2006, she won by less than 1 percent of the vote, and the district also split its 2004 presidential vote between George W. Bush and John F. Kerry, 50 percent to 49 percent.

\section{Notes}

1. The authors gratefully acknowledge support from NSF grant \# 0429452. Any opinions, findings, and conclusions or recommendations expressed in this material are those of the authors and do not necessarily reflect the views of the National Science Foundation.

2. The Senator was Carl Levin. The twelve representatives were Earl Blumenauer, Michael Capuano, James Clyburn, Mike Conaway, Anna Eshoo, Jack Kingston, Zoe Lofgren, Don Manzullo, Jim Matheson, David Price, George Radanovich, and Dave Weldon.

\section{References}

Bellamy, C., and J. Taylor. 1998. Governing in the Information Age. Buckingham: Open University Press.

Bessette, J. M. 1994. The Mild Voice of Reason: Deliberative Democracy and American National Government. Chicago: University of Chicago Press.

Bianco, W. T. 1994. Trust: Representatives and Constituents. Ann Arbor: University of Michigan Press.

Bimber, B. A. 2003. Information and American Democracy: Technology in the Evolution of Political Power. Cambridge: Cambridge University Press.

Bohman, J., and W. Rehg, eds. 1997. Deliberative Democracy: Essays on Reason and Politics. Cambridge: MIT Press.

Congressional Management Foundation (CMF). 2001. "Constituents and Your Website: What Citizens Want to See on Congressional Websites." Accessed December 1, 2010. http://www.cmfweb.org/storage/cmfweb/documents/CMF _Pubs/constituentsandwebsites.pdf.

Dawes, Sharon S., Peter A. Bloniarz, and Kristine L. Kelly. 1999. Some Assembly Required: Building a Digital Government for the 21st Century. Albany, N.Y.: Center for Technology in Government. 
DiMaggio, P. J., E. Hargittai, W. R. Neuman, and J. P. Robinson. 2001. "Social Implications of the Internet." Annual Review of Sociology 27:307-336.

Esterling, Kevin M., David M.J. Lazer, and Michael A. Neblo. 2011. "Representative Communication: Website Interactivity and 'Distributional Path Dependence' in the U.S. Congress." Political Communication, forthcoming.

Esterling, Kevin M., Michael A. Neblo, and David M.J. Lazer. . 2011a. "Estimating Treatment Effects in the Presence of Noncompliance and Nonresponse: The Generalized Endogenous Treatment Model." Political Analysis, forthcoming.

Esterling, Kevin M., Michael A. Neblo, and David M.J. Lazer.2011b. “Means, Motive, and Opportunity in Becoming Informed about Politics: A Deliberative Field Experiment with Members of Congress and Their Constituents." Public Opinion Quarterly, forthcoming.

Fishkin, J. 1997. The Voice of the People: Public Opinion and Democracy. New Haven: Yale University Press.

Folk, Nicole, and Kathy Goldschmidt. 2003. "Congress Online 2003: Turning the Corner on the Information Age." Congress Online Project. Accessed December 1, 2010. http://www.cmfweb.org/storage/cmfweb/documents/CMF _Pubs/congressonline2003.pdf.

Fountain, J. E. 2001. Building the Virtual State: Information Technology and Institutional Change. Washington, DC: Brookings.

Gutmann, A., and D. Thompson. 1997. Democracy and Disagreement. Cambridge: Harvard University Press.

Habermas, J. 1996. Between Facts and Norms: Contributions to a Discourse Theory of Law and Democracy. Cambridge: MIT Press.

Heclo, H. 1974. Modern Social Politics in Britain and Sweden: From Relief to Income Maintenance. New Haven: Yale University Press.

Held, D. 1996. Models of Democracy. Oxford: Polity Press.

Hibbing, J., and E. Theiss-Morse. 2002. Stealth Democracy: Americans' Beliefs about How Government Should Work. Cambridge: Cambridge University Press.

Hindman, M. S. 2009. The Myth of Digital Democracy. Princeton, NJ: Princeton University Press.

Lazer, David, Ines A. Mergel, Curtis E. Ziniel, Kevin M. Esterling, and Michael A. Neblo. 2009. "Networks, Hierarchies, and Markets: Aggregating Collective Problem Solving in Social Systems.” June 2. HKS Working Paper No. RWP09_17. Accessed December 1, 2010. http://ssrn.com/abstract=1413298.

Lazer, D., M. Neblo, K. Esterling, and K. Goldschmidt. 2009. "Online Townhalls: Exploring Democracy in the Twenty-first Century." Congressional Management Foundation. Accessed December 1, 2010. http://www.cmfweb.org/ storage/cmfweb/documents/CMF_Pubs/online-town-hall-meetings.pdf.

Lazer, David, Anand E. Sokhey, Michael A. Neblo, and Kevin M. Esterling. 2010. "Deliberative Ripples: The Network Effects of Political Events." Accessed December 1, 2010. http://ssrn.com/abstract $=1656553$. 
Lupia, A., and M. D. McCubbins. 1998. The Democratic Dilemma: Can Citizens Learn What They Need to Know? New York: Cambridge University Press.

Madison, James. 2003. In Alexander Hamilton, James Madison, and John Jay, The Federalist Papers. No. 56. New York: New American Library.

Mayer-Schönberger, V., and D. Lazer. 2007. Governance and Information Technology: From Electronic Government to Information Government. Cambridge: MIT Press.

Neblo, M. A. 2000. "Thinking through Democracy: Deliberative Politics in Theory and Practice." Unpublished dissertation, University of Chicago.

Neblo, Michael A., Kevin M. Esterling, Ryan Kennedy, David Lazer, and Anand E. Sokhey. 2010. "Who Wants to Deliberate-and Why?" American Political Science Review 104:566-583.

Pitkin, H. F. 1967. The Concept of Representation. Berkeley: University of California Press.

Yates, J., W. J. Orlikowski, and K. Okamura. 1999. "Explicit and Implicit Structuring of Genres in Electronic Communication: Reinforcement and Change of Social Interaction.” Organization Science 10, no. 1:83-103. 